\title{
Adsorption of gold(III) from waste rinse water of semiconductor manufacturing industries using Amberlite XAD-7HP resin
}

\author{
Nghiem Van Nguyen ${ }^{a, b}$, Jae-chun Lee ${ }^{b, *}$, Soo-kyoung Kim ${ }^{b}$ \\ Manis Kumar $\mathrm{Jha}^{\mathrm{c}}$, Kang-Sup Chung ${ }^{\mathrm{b}}$ and Jinki Jeong ${ }^{\mathrm{b}}$ \\ www.goldbulletin.org
}

\begin{abstract}
Advanced hydrometallurgical separation processes are gaining significant importance for the recovery of gold from the aqueous solutions viz. leach liquor of waste electronics, plating material solutions, and waste wash water from electronic industries. In the present investigation, gold adsorption from the waste rinse water of semiconductor manufacturing industries is reported using Amberlite XAD7HP. For experimental purposes, chloride waste rinse water that contained primarily Au $(281 \mathrm{mg} /$ L) with trace amounts of $\mathrm{Cu}, \mathrm{Ni}, \mathrm{Zn}, \mathrm{Sn}$ etc was used. Batch studies were carried out to optimize various process parameters, including contact time, acidity of solution, and resin dosage for the adsorption of gold from the above waste effluent. Adsorption of $\mathbf{9 2 . 2 5 \%}$ gold was found from the waste solution within a contact time of 30 minutes at an aqueous to resin (A/R) ratio of $25 \mathrm{~mL} / \mathrm{g}$ and an equilibrium $\mathrm{pH}$ of 0.63 . In optimal conditions, the loading capacity of resin for gold was observed to be $58.82 \mathrm{mg}$ of gold/g of resin. The gold adsorption phenomena were confirmed by the comparative FT-IR spectroscopic characterization studies of fresh resin and gold
\end{abstract}

\footnotetext{
a Resources Recycling, University of Science and Technology, Daejeon 305-350, Republic of Korea

${ }^{b}$ Mineral Resources Research Division, Korea Institute of Geoscience and Mineral Resources (KIGAM), Daejeon 305-350, Republic of Korea

Metal Extraction \& Forming Division, National Metallurgical

Laboratory (CSIR), Jamshedpur, India

* Corresponding author. Tel: +82-42-868-3613,

Fax: +82-42-868-3415, E-mail: jclee@kigam.re.kr
}

Keywords: adsorption, Amberlite XAD-7HP, waste rinse water, gold loaded resin. Elution tests were carried out for the elution of gold from the gold loaded resin using various ratio mixtures of acetone and $1.0 \mathrm{M} \mathrm{HCl}$. An elution efficiency of $96.96 \%$ gold was achieved at an acetone-to-acid ratio of 9 . In this condition, gold-enriched solution containing $7,240 \mathrm{mg}$ gold/ $\mathrm{L}$ was obtained. The maximum elution of gold was found to be $99.33 \%$ using pure acetone in a contact time of $\mathbf{3 0}$ minutes. The data obtained will be useful to simulate the continuous gold adsorption process within a column.

\section{Introduction}

For the rapid and accurate transmission of digital information electronic equipment requires an efficient and reliable conductor. Gold fulfills the conductor requirements better than any other metal due to its high corrosion resistance, thermal properties, and electrical conductivity. Therefore, in electronic industries, gold is used for connectors, switches, relay contacts, soldered joints, connecting wires, and connection strips. The processing and manufacturing of electronic parts involves various steps, such as electroplating, etching, rinsing, and chemical and mechanical polishing (CMP). During the manufacturing of electronic parts, wastewater containing various valuable and precious metals is generated and requires recycling. As previously reported, electronic process waste is one of the major contributors to heavy metal pollution in surface water [1]. In the semiconductor manufacturing industry, waste rinse water containing gold is generated and requires recycling in order to obtain this precious metal. Gold recovery from aqueous solutions has received significant attention because gold is present in appreciable amounts in electronic parts and plating materials [2]. 
The recovery of gold from waste solution is usually carried out by conventional methods such as precipitation [3], solvent extraction with dibutyl carbitol (DBC) $[4,5]$ or methyl isobutyl ketone (MIBK) [6, 7], adsorption [8], and ion exchange [9]. Many sorbents have been proposed for gold recovery, including activated carbon, persimmon tannin gel, neem leaf broth, tannin, fungal biomass, ion-exchange resins [2], etc. Adsorption of metals using solid resin is a proven technique for the purification and separation of metals from different aqueous solutions [10]. The main advantages of adsorption using ion exchange resins over other techniques are the high selectivity, less sludge volume produced, ease of regeneration, and the ability to meet strict discharge specifications.

For the recovery of gold from waste solution, many studies have made use of resins. Several authors have reported the adsorption of gold using ion exchange resins such as Lewatit MP-64 [11] and chitosan resin [12]. Some strong anion resins, such as purolite A-500 [13], Dowex 21K [14], and Dowex G-55 [14, 15] have been used for the adsorption of gold due to their fast loading rates and high capacity. The difficulty for using strong anion resins remains in the elution step due to the great strength of ion adsorption [16] which has also been reported by Alguacil [11]. Among the available resins, Amberlite resin is considered a good choice for the adsorption of gold. Some studies have been carried out on the adsorption of gold from waste solution using Amberlite XAD 2000 [17], XAD-4, XAD-7, and XAD8 resins $[18,19]$. Because of the good adsorption properties, including the large surface area and hydrophobic nature Amberlite XAD-7 has been used effectively for the recovery of gold from waste solution [20]. Harris et al. [21] mentioned that polymeric acrylic ester adsorbent ion exchange resins, such as Amberlite XAD-7 and XAD-8, are highly effective and selective for removing gold from precious and base metal-bearing chloride or mixed chloride / sulfate solution. Additionally, these resins can be eluted simply and without loss of subsequent loading capacity. In that patent, the authors reported that gold is selectively adsorbed by Amberlite XAD-7 resin at $\mathrm{pH}=0$, while other elements such as palladium, platinum, copper, iron, bismuth, and rhodium are not adsorbed at all. Due to the sufficient pore size, $\mathrm{AuCl}_{4}^{-}$can migrate through the pores rather than the adsorbent surface [22]. The mechanism for adsorption of gold on Amberlite XAD-7HP might be caused by the interaction between protonated oxygen atoms of polyacrylate and chloro-complexes to form $=\mathrm{OH}^{+} \mathrm{AuCl}_{4}$. With the aim to establish closed processes to treat waste rinse water generated during the manufacturing of electronic products, adsorption techniques using resins have been employed to recover valuable metals and precious metals.

In the present investigation, gold adsorption from the rinse water of semiconductor manufacturing industries using Amberlite XAD-7HP resin has been reported. The effect of various process parameters, viz. contact time, acidity of solution, and resin dosage was studied in relation to adsorption of gold. The gold adsorption phenomena were confirmed by the comparative FT-IR spectroscopic characterization studies of fresh resin and gold loaded resin.

\section{Generation of waste in the semiconductor industry}

In semiconductor devices, gold circuit patterns are formed on a substrate using well-established techniques [23]. Firstly, a layer of light-sensitive material (photoresist) is deposited on a seed layer of gold. Ultraviolet light is used to shine on the photoresist layer through a mask to define circuit patterns. The ultraviolet light hardens the photoresist layers in areas defined by the mask. Gold plating is then performed to deposit 6 to 7 microns of gold. Finally, gold etching is performed with a solution of aqua regia, potassium iodide (iodine), or cyanide to remove a portion of the electroplated gold and the exposed seed layer of gold. In this process, the spent etch solution containing gold is generated. Korean environmental regulations restrict the use of cyanide. The electronic company is using reverse aqua regia $\left(\mathrm{HCl}: \mathrm{NHO}_{3}=1: 3\right)$ to remove gold in the etching process. After finishing the process of making a gold circuit pattern, water is used to wash the etched solution. In the presence of high chloride concentration, the main chemical form of gold (III) ion in aqueous solution is $\left[\mathrm{AuCl}_{4}\right]^{-}$. The only known intermediate form is $\mathrm{AuCl}_{3} \mathrm{OH}^{-}$, which is the hydrolyzed at low $\mathrm{HCl}$ concentration [19].

\section{Materials and methods}

\section{Materials}

Waste rinse water containing gold used for experimental purposes was supplied by Korean semiconductor company. The specifications of waste rinse water are given in Table 1. The concentration of the acid and gold was $8.0 \mathrm{M} \mathrm{H}_{3} \mathrm{O}^{+}$and $281 \mathrm{mg} / \mathrm{L}$, respectively. Chemical reagents (sodium hydroxide, 
Table 1 Specifications of waste rinse water

\begin{tabular}{|cc|}
\hline Elements & Concentration (mg/L) \\
\hline $\mathrm{Au}$ & 281.00 \\
$\mathrm{Cu}$ & 0.30 \\
$\mathrm{Ni}$ & 0.96 \\
$\mathrm{Zn}$ & 0.23 \\
$\mathrm{Sn}$ & 1.30 \\
$\mathrm{Fe}$ & $\mathrm{ND}$ \\
$\mathrm{Co}$ & $\mathrm{ND}$ \\
$\mathrm{Pb}$ & $\mathrm{ND}$ \\
$\mathrm{Cl}^{-}$ & 74,550 \\
$\mathrm{NO}_{3}^{-}$ & 365,800 \\
$\mathrm{H}^{+}$ & 8,000 \\
$\mathrm{ND}: \mathrm{not}$ detected & \\
\hline
\end{tabular}

Table 2 Characteristic properties of Amberlite XAD-7HP resin

\begin{tabular}{|ll|}
\hline Matrix & $\begin{array}{l}\text { Macroreticular aliphatic } \\
\text { crosslinked polymer }\end{array}$ \\
\hline Physical form & White translucent beads \\
Moisture holding capacity & 61 to $69 \%$ \\
Specific gravity & 1.06 to 1.08 \\
Harmonic mean size & $0.56-0.71 \mathrm{~mm}$ \\
Uniformity coefficient & $\leq 2.0$ \\
Fines content & $<0.3 \mathrm{~mm}: 7 \%$ max \\
Coarse beads & $>1.18 \mathrm{~mm}: 8 \%$ max \\
Surface area & $450 \mathrm{~m}^{2} / \mathrm{g}$ \\
Porosity & $\geq 0.5 \mathrm{~mL} / \mathrm{mL}$ \\
\hline
\end{tabular}

calcium oxide and acetone) were laboratory reagent grade. Amberlite XAD-7HP resin supplied by the Rohm and Hass Company was used for gold adsorption. The characteristic resin properties are presented in Table 2. Resin was washed with 1.0 M hydrochloric acid to remove any impurities and organics. Afterwards, the resin was washed several times with de-ionized water to remove excess acid and dried for $12 \mathrm{~h}$ in a $50^{\circ} \mathrm{C}$ oven.

\section{Methods}

Batch experiments for the adsorption of gold from the rinse water of semiconductor manufacturing industries were carried out in a conical flask attached to a wrist-action shaking-machine at atmospheric condition using Amberlite XAD-7HP resin. After the adsorption of gold, the resin was separated from the raffinate with the filter paper (Whatman no. 41). The gold-loaded resin obtained from cumulative loading of gold in batch experiments was eluted in vertical columns of $0.9 \mathrm{~cm}$ diameter and $25 \mathrm{~cm}$ height to create the gold-enriched solution. The flow rate of solution in the column was controlled by the adjustment of a stopcock. Bed volume was determined by adding a weighed amount of resin into a $25 \mathrm{~mL}$ cylinder and then immersing the resin into water. Eluted solutions were evaporated by heating to release acetone. Next, the dried samples were dissolved with hydrochloric acid and diluted with de-ionized water before sampling and analysis. The aqueous raffinate and eluate were analyzed for gold content by atomic absorption spectroscopy (AAnalyst 400, PerkinElmer Inc., USA). The structures of the original resin and gold-loaded resin were determined by Fourier transform infrared spectroscopy (FT-IR, NICOLET 380, USA).

\section{Results and discussion}

\section{Effect of contact time}

The effect of contact time for adsorption of gold by Amberlite XAD-7HP resin was determined using 1.0 $\mathrm{g}$ of resin and $25 \mathrm{~mL}$ of original acidic waste solution in different conical flasks. The flasks were shaken for different time intervals at room temperature (room temperature was maintained by a temperature controller fitted with the shaking-machine). To study the effect of time on gold adsorption, the $\mathrm{pH}$ of the waste solution was adjusted to 0.63 (acidity is 0.23

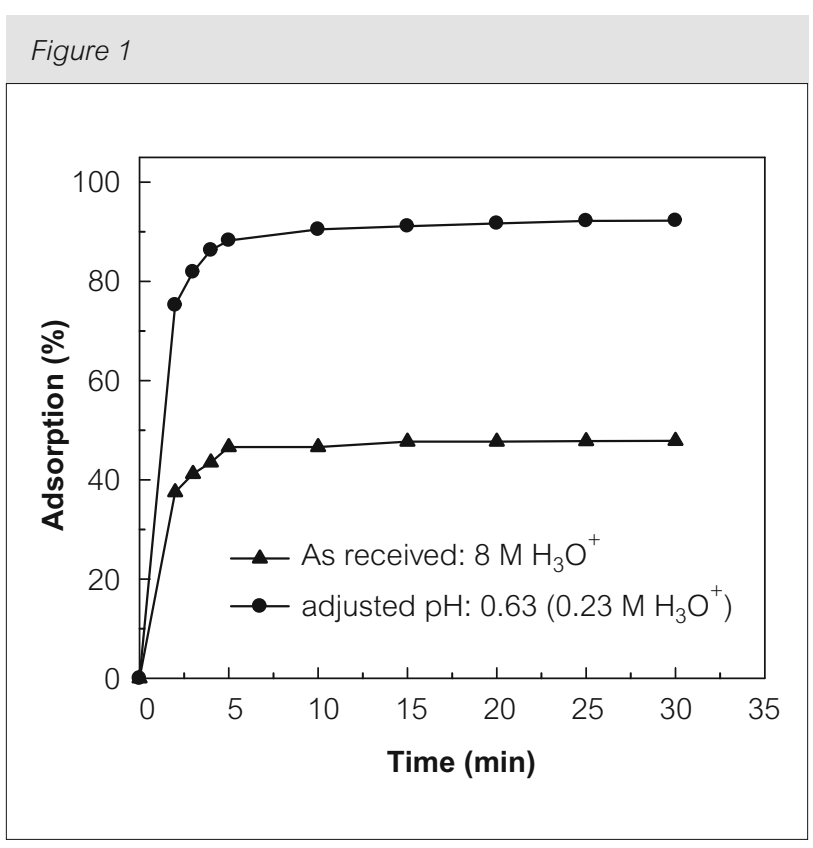

Effect of contact time for adsorption of gold ( $A=$ gold chloride solution; $R=$ Amberlite $X A D-7 H P$ resin; $A / R=25$ ) 
$\mathrm{M})$ by addition of $\mathrm{NaOH}$. The percentage adsorption is plotted against time in Fig. 1. A smooth curve leading to equilibrium adsorption of gold complexes on the resin was obtained. With increasing the contact time from 2 to 30 minutes, the percentage adsorption of gold from the original waste solution (without $\mathrm{pH}$ adjustment) was found to increase from $37.50 \%$ to $46.85 \%$. Similarly, from the $\mathrm{pH}$ adjusted solution, the adsorption of gold was found to increase from $75.23 \%$ to $92.25 \%$. Subsequent increases in time had no effect on the adsorption of gold. Therefore, the maximum contact time of 30 minutes was suitable to reach the equilibrium of the adsorption reaction.

\section{Kinetics of adsorption}

The kinetics of adsorption expresses the rate of gold complex uptake on the resin and also the rate controlled equilibrium time. The data for gold adsorption obtained from the solution containing $281 \mathrm{mg}$ gold/L, under various contact times with Amberlite XAD-7HP resin, were calculated to determine the order of the reaction rate. Well-known kinetic expressions, namely, pseudo-first and second order, were used to fit the experimental data [24]. The pseudo-first order rate expression of Lagergren $[25,26]$ is generally described by the following equation:

$\frac{d q}{d t}=k_{l}\left(q_{e}-q\right)$

where $q_{e}$ and $q$ are the amounts of gold complex ions $(\mathrm{mg} / \mathrm{g})$ adsorbed on the resin at equilibrium and at time $t$, respectively, and $k_{1}$ is the rate constant $\left(\min ^{-1}\right)$. Integrating and applying the boundary conditions, $t=0$ and $q=0$ to $t=t$ and $q=q_{e}$ at maximum equilibrium adsorption, the equation can be expressed in the form:

$\log \left(q_{e}-q\right)=\log q_{e}-\frac{k_{1}}{2.303} t$

The slope for fitting of the first order rate is presented in Fig. 2. The rate constant $k_{1}$ was obtained from the slope of linear plots log $\left(q_{e}-q\right)$ against $t$ for $281 \mathrm{mg} /$ $\mathrm{L}$ of gold aqueous feed with $k_{1}=0.198\left(\mathrm{~min}^{-1}\right)$. The value of the correlation coefficient was given from a linear regression of $R^{2}=0.948$.

The pseudo- second order reaction is greatly influenced by the amount of metal on the adsorbent's surface and the amount of metal adsorbed at equilibrium [1]. The pseudo-second-order rate reaction was also analyzed by fitting the same data for gold adsorption and described by the following equation:

$\frac{d q}{d t}=k_{2}\left(q_{e}-q\right)^{2}$

where $k_{2}$ is the rate constant of pseudo-second order sorption (g/mg.min). Integrating and applying boundary conditions, $t=0$ and $q=0$ to $t=t$ and $q=q_{e}$ Eq. (3) can be written in a linear form as:

$\frac{t}{q}=\frac{1}{h}+\frac{1}{q_{e}} t$

where $\mathrm{h}=k_{2} q_{e}^{2}$ is the initial sorption rate.

The plot of $(t / q)$ against $t$ for the above equation should give a linear relationship from which the constants $k_{2}$ can be determined for an aqueous feed of $281 \mathrm{mg} / \mathrm{L} \mathrm{Au}$ (Fig. 3) with $k_{2}=0.4$ ( $\mathrm{g} / \mathrm{mg} \cdot \mathrm{min}$ ) and a correlation coefficient of $R^{2}=1$. The correlation coefficient $R^{2}$ for the second order rate was found greater than that of the first order. Thus, the second order rate expression fits the data most satisfactorily.

\section{Effect of acidity in the waste rinse water}

Waste rinse water is highly acidic around 8.0 $\mathrm{M} \mathrm{H}_{3} \mathrm{O}^{+}$: therefore, the effect of acidity in waste

\section{Figure 2}

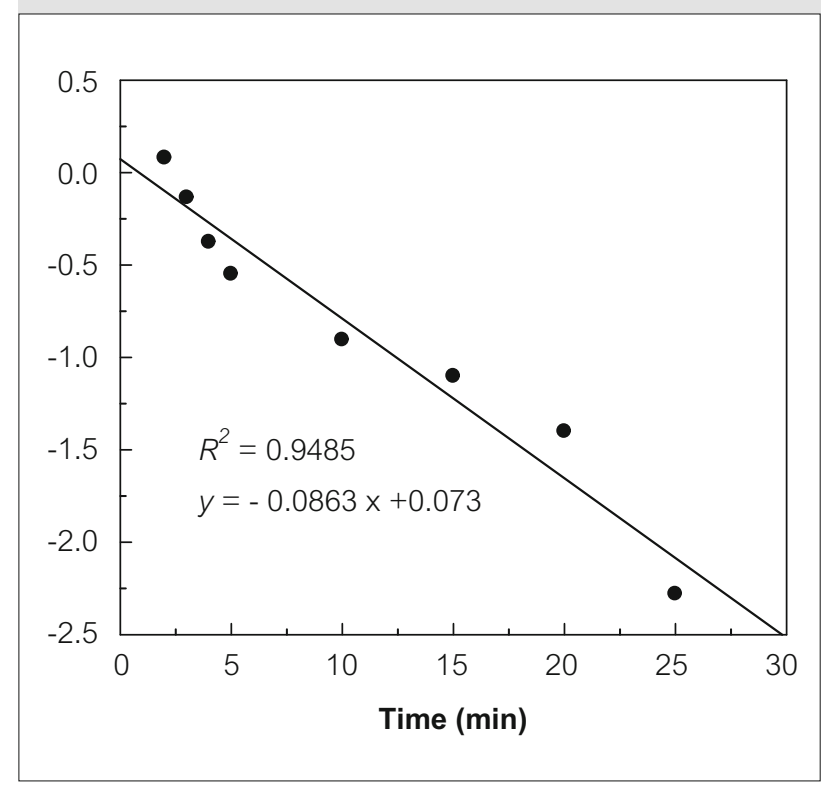

Fitting of the first order rate for gold adsorption onto Amberlite XAD-7HP resin 


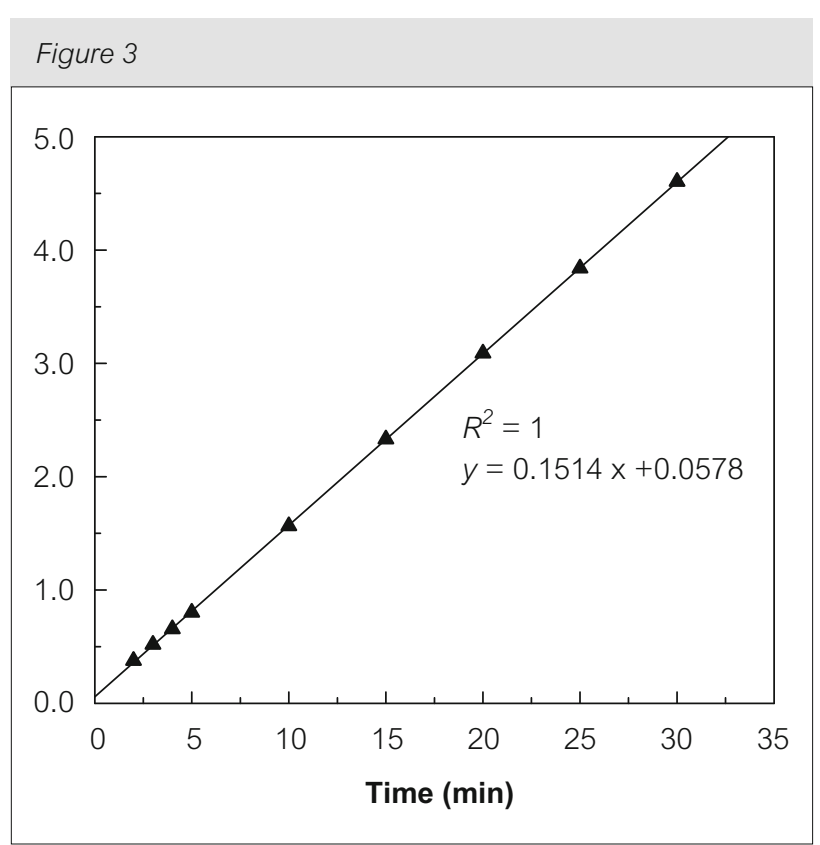

Fitting of the second order rate for gold adsorption onto Amberlite XAD-7HP resin

solution on the adsorption of gold using XAD-7HP resin was investigated. The acidic solution was neutralized by adding $\mathrm{NaOH}$ or $\mathrm{CaO}$. The results presented in Fig. 4 show that gold adsorption increased by decreasing the acidity of the waste solution. As we know that gold existed in chlorocomplex $\mathrm{HAuCl}_{4}$, the dissociation of gold chlorocomplex can be expressed by the equation:

$\mathrm{HAuCl}_{4} \leftrightarrow \mathrm{AuCl}_{4}^{-}+\mathrm{H}^{+}$

At high acidity, the equilibrium tends to shift towards the left side: therefore, the gold is present in the aqueous phase in the form of the non-adsorbable $\mathrm{HAuCl}_{4}$ species. From Fig. 4, the adsorption percentage of gold reached $92.25 \%$ at solution $\mathrm{pH}$ of $0.63\left(0.23 \mathrm{M} \mathrm{H}_{3} \mathrm{O}^{+}\right)$.

\section{Effect of resin dose}

The effect of resin amount on gold adsorption from waste rinse water (adjusted feed $\mathrm{pH}=0.63$ ) was investigated at a contact time of 30 minutes. A solution volume of $25 \mathrm{~mL}$ was used, and the resin dose was varied from 0.1 to $3.0 \mathrm{~g}(8.33-250 \mathrm{~mL}$ aqueous solution/g of resin). The results presented in Fig. 5 indicate that gold adsorption increased with increasing resin dose. It is apparent that the amount of metal ions adsorbed per unit mass increases with increasing resin amount. The fraction of metal removed from the aqueous phase increased with increasing adsorbent dose in the batch vessel for a

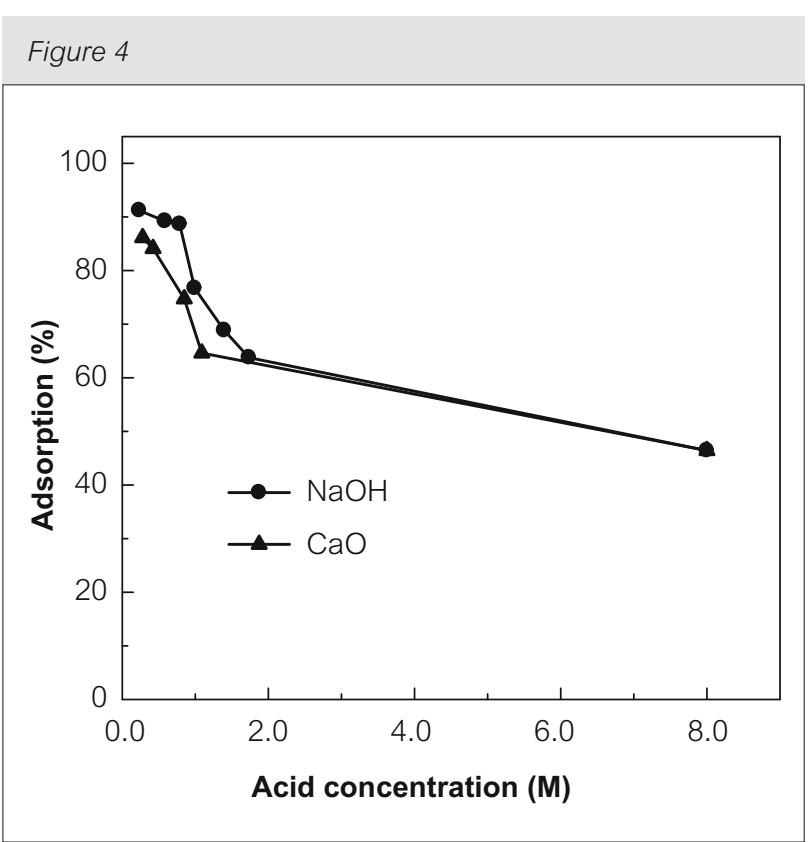

Effect of acidity for adsorption of gold using Amberlite XAD$7 H P$ resin $(A=$ gold chloride solution; $R=$ Amberlite $X A D-7 H P$ resin; $A / R=25$; contact time $=30$ mins)

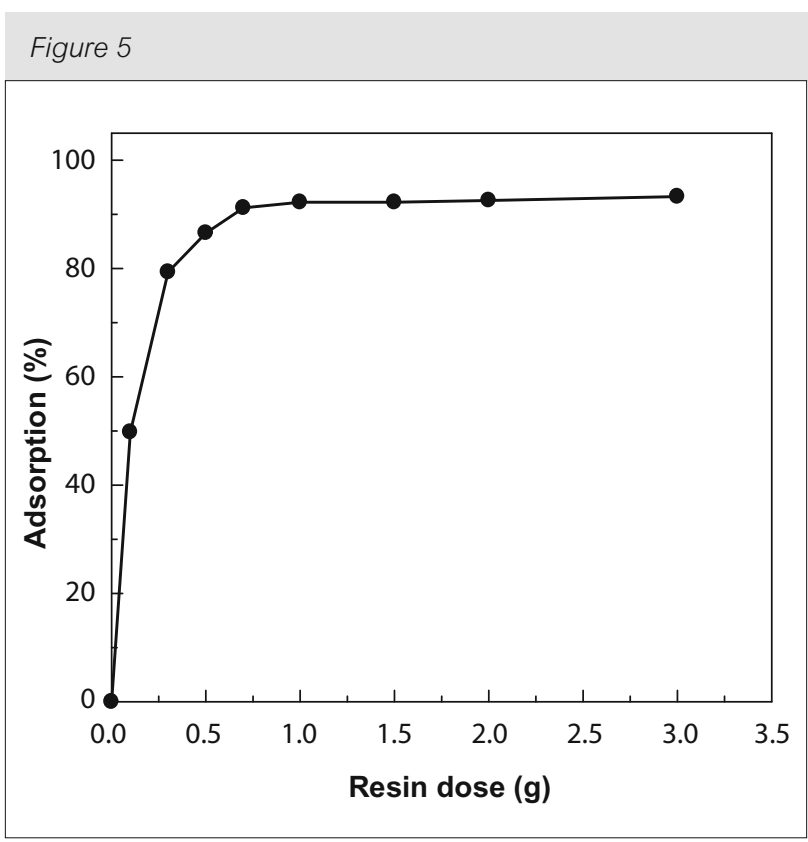

Effect of resin dose for adsorption of gold ( $A=$ gold chloride solution; $R=$ Amberlite $X A D-7 H P$ resin; adjusted feed $p H=0.63$; contact time $=30$ mins)

fixed initial metal concentration. In this experiment, a resin dosage from 0.1 to $1.0 \mathrm{~g}(25-250 \mathrm{~mL}$ solution $/ \mathrm{g}$ of resin) resulted in the adsorption of gold increasing from $49.76 \%$ to $92.25 \%$, while further increase of a resin dose from 1.0 to $3.0 \mathrm{~g}(8.33-25 \mathrm{~mL}$ solution $/ \mathrm{g}$ of resin) gave a smaller increase in gold adsorption 
as expected. It may be concluded that, by increasing the adsorbent dose, the removal efficiency increases but adsorption density decreases. The decrease in adsorption density can be attributed to the fact that some of the adsorption remains unsaturated during the sorption process whereas the number of available adsorption sites increase by an increase in sorbent, thereby resulting in an increase in removal efficiency $[1,27]$.

\section{Loading capacity}

The studies were carried out to determine the loading capacity of resin. With 1.0 gram of resin added to a conical flask, $25 \mathrm{~mL}$ of waste rinse water (adjusted feed $\mathrm{pH}=0.63$ ) containing gold was added for a contact time of 30 minutes. The repeated contacts with the same resin were made with waste solution until an equilibrium adsorption of gold was achieved. In the first stage of contact, the adsorption of gold was found to be $6.5 \mathrm{mg}$ gold/g of resin. In subsequent stages of contact, the extraction of gold from the aqueous feed decreased, as the available site for the adsorption decreased in each subsequent contact. A cumulative adsorption at an aqueous to resin ratio of 25 in 15 stages was found to be $58.82 \mathrm{mg}$ gold/ $\mathrm{g}$ of resin. The adsorption isotherm expresses the amount of solute adsorbed per unit of adsorbent as a function of equilibrium concentration in bulk solution at constant temperature. The adsorption isotherm of resin for gold is presented in Fig. 6. Satisfactory material balance was obtained upon comparing the

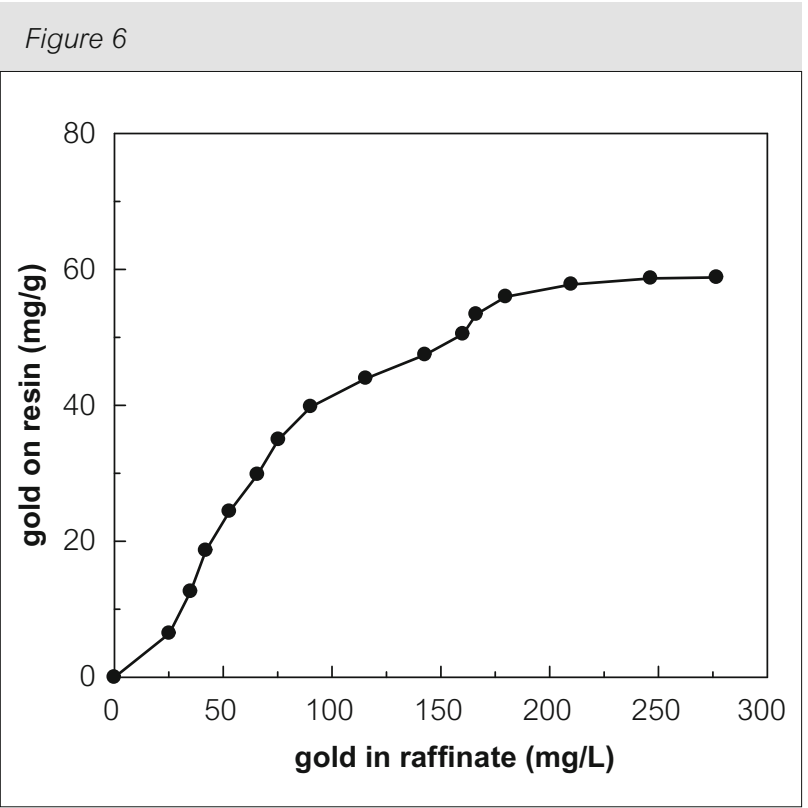

Adsorption isotherm of resin for adsorption of gold $(A=$ gold chloride solution; $R=A$ mberlite $X A D$-7HP resin; adjusted feed $p H=0.63 ; A / R=25)$ results of gold adsorbed and eluted with mixtures of acetone and hydrochloric acid.

\section{Resin characterization by FT-IR}

FT-IR spectra of original and gold-loaded Amberlite XAD-7HP resin were recorded and are presented in Fig. 7. IR peak assignments for the matrix are listed in Table 3. Amberlite XAD-7HP is an acrylic ester that contains ester group $\mathrm{O}-\mathrm{C}=\mathrm{O}$. All esters give rise to three strong infrared bands that appear at approximately 1700,1200 , and $1100 \mathrm{~cm}^{-1}$. The spectrum for the acrylic ester of Amberlite XAD7HP exhibits a strong band at $1735.10 \mathrm{~cm}^{-1}$, which represents the $\mathrm{C}=\mathrm{O}$ stretch of the ester group. The band at $1251.44 \mathrm{~cm}^{-1}$ appeared due to the asymmetric stretching of the $\mathrm{C}-\mathrm{C}$ and $\mathrm{C}-\mathrm{O}$ bonds attached to the carbonyl carbon. This vibration C-C-O stretch involves the left side of the ester functional group. The band at $1145.76 \mathrm{~cm}^{-1}$ is due to a vibration involving the ester oxygen and the next two carbons attached to it in the hydrocarbon chain [28]. These peaks were also presented in Saikia's

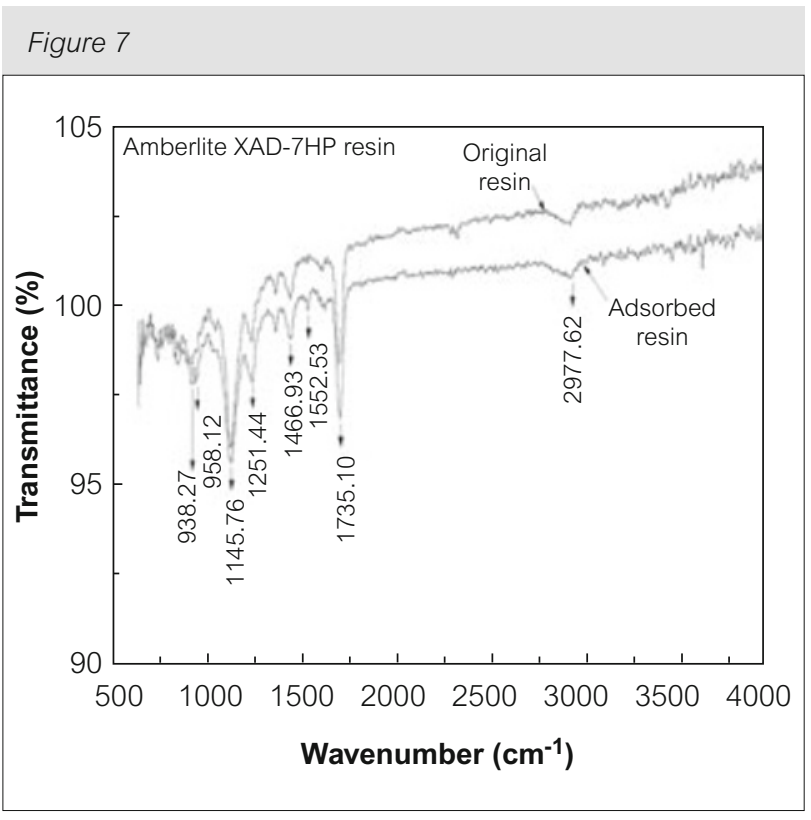

FTIR spectra of Amberlite XAD-7HP resin

Table 3 Fundamental frequencies of the acrylic ester in Amberlite XAD-7HP resin

\begin{tabular}{|cr|}
\hline Frequency $\left.\mathbf{( c m}^{-1}\right)$ & Assignments \\
\hline 2977.62 & C-H stretch \\
1735.10 & C=O stretch \\
1251.44 & C-C-O stretch \\
1145.76 & O-C-C stretch \\
\hline
\end{tabular}


study [29] to observe the structure of Amberlite XAD-7 by FTIR. The peak at $2977.62 \mathrm{~cm}^{-1}$ may be due to the presence of $\mathrm{C}-\mathrm{H}$ stretching $[28,29]$. The difference between before and after adsorption of gold was shown at a peak of $1552.53 \mathrm{~cm}^{-1}$ which is near the ester group $\mathrm{C}=\mathrm{O}$. This might be caused by the interaction between the protonated oxygen atom of the ester group $\mathrm{C}=\mathrm{O}$ with chloro-complex [18], proving the presence of gold on the resin.

\section{Elution test}

The studies for the elution of gold from gold-loaded resin were carried out with varying concentration $(1.0-3.0 \mathrm{M})$ of hydrochloric acid. The results presented in Fig. 8 indicate that the hydrochloric acid is not a suitable reagent for the elution of gold as it eluted negligible amounts of gold. The elution studies of gold from loaded resin were further carried out using acetone and mixtures of acetone and 1.0 $\mathrm{M}$ hydrochloric acid. The maximum elution of gold was found to be $99.33 \%$ using pure acetone at an $\mathrm{A} / \mathrm{R}$ ratio of 25 with a contact time of 30 minutes. Acetone is an effective reagent for the elution of gold from loaded resin and also evaporates easily in pure form. Therefore, the elution solution used in the studies was prepared by mixing acetone and hydrochloric acid.

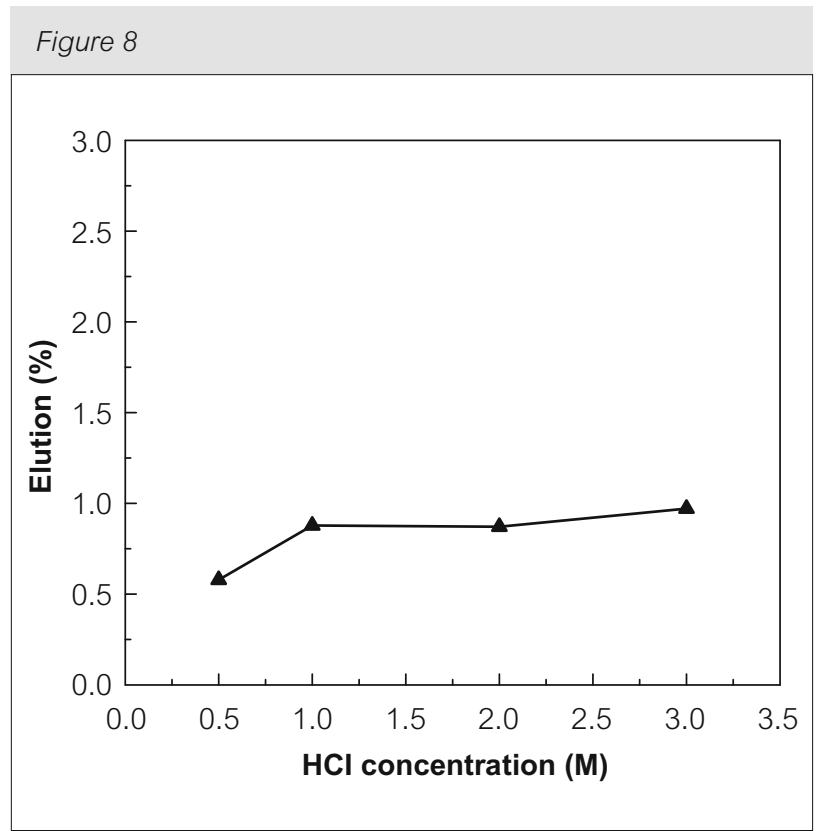

Elution of gold from loaded resin using varying concentrations of hydrochloric acid (Resin= $6.53 \mathrm{mg}$ gold loaded/gram of resin Amberlite $X A D-7 H P$, Elution solution = hydrochloric acid, $A / R=25$, Contact time $=30$ mins)
For the elution test, gold-loaded resin was prepared from waste solution containing $281 \mathrm{mg}$ gold/L at feed $\mathrm{pH}$ of 0.63 . Resin loaded with $6.53 \mathrm{mg}$ gold $/ \mathrm{g}$ was in contact with the mixture of eluents, acetone, and hydrochloric acid with varying mixing ratios at a 30-minute fixed contact time. Fig. 9 shows that the

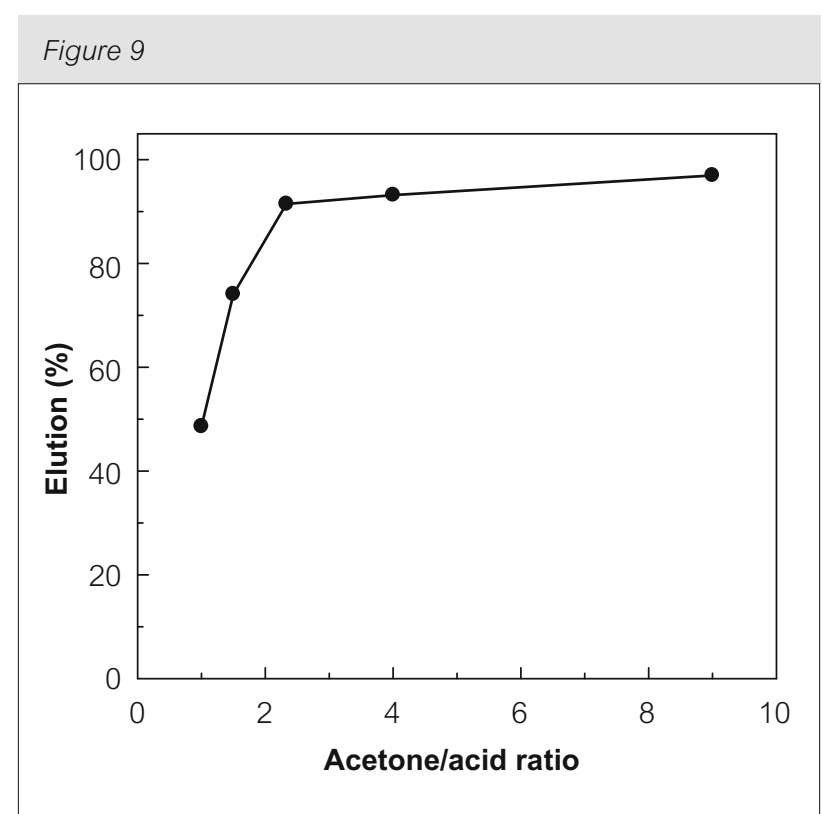

Elution of gold using mixtures of acetone and hydrochloric acid (Resin $=6.53 \mathrm{mg}$ gold loaded/gram of resin Amberlite XAD-7HP, $A / R=25$, Contact time $=30 \mathrm{mins}$ )

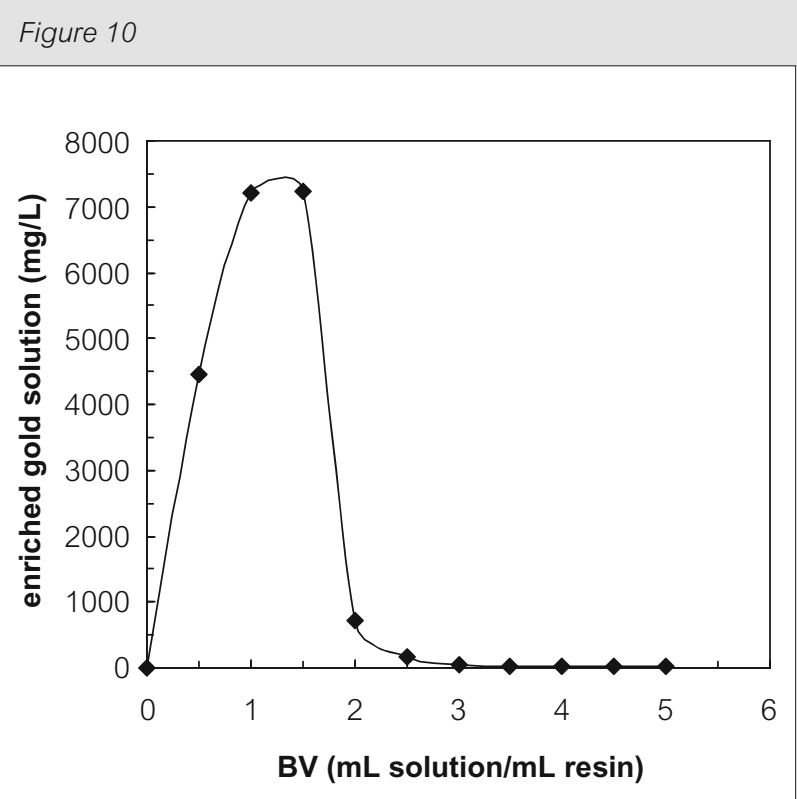

Enrichment of gold from loaded resin using mixtures of acetone and hydrochloric acid (Bed Volume $=4.6 \mathrm{~mL}$; Resin= $58.82 \mathrm{mg}$ gold loaded/gram of resin Amberlite XAD-7HP, Flow rate $=0.88$ $\mathrm{mL} / \mathrm{min}$ ) 
percentage elution increased with an increasing ratio of acetone and hydrochloric acid. The elution of $96.96 \%$ of gold from the loaded resin was obtained using a mixture of acetone and hydrochloric acid at a ratio of 9.0. The gold-loaded resin was obtained from the repeated contact of the same resin with the waste solution (adjusted feed $\mathrm{pH}=0.63$ ). It was used for gold elution and solution enrichment tests in a column having a diameter of $0.9 \mathrm{~cm}$. Fig. 10 shows that a concentration of $7,240 \mathrm{mg}$ gold/L of eluted solution could be obtained which is 25 times more in comparison to the concentration of waste rinse water used for experimental purposes.

\section{Conclusions}

The results of this research showed that the $\mathrm{pH}$ of the solution played an important role in the adsorption of gold using Amberlite XAD-7HP. The adsorption of $46.85 \%$ of gold was obtained from original waste solutions with the high acidity of $8.0 \mathrm{M} \mathrm{H}_{3} \mathrm{O}^{+}$. When the acidity of the solution decreased by adding alkali, the adsorption of gold increased and reached $92.25 \%$ at a feed $\mathrm{pH}$ of 0.63 . The elution of gold from loaded resin was found to be effective using a mixture of acetone and hydrochloric acid. The enrichment of gold from gold-loaded resin showed that the concentration of gold could be enriched in the solution up to 25 times the initial feed solution using Amberlite XAD-7HP resin. The data obtained will be useful to simulate the continuous mode gold enrichment process from wastewater using Amberlite XAD-7HP resin.

\section{Acknowledgements}

This paper is based on work supported by the Korea Institute of Energy Technology Evaluation and Planning (KETEP) under the project entitled "Development of High Efficiency and Energy Saving Technology for the Recovery of Precious Metals Using Hydrocyclone Reactor".

\section{About the authors}

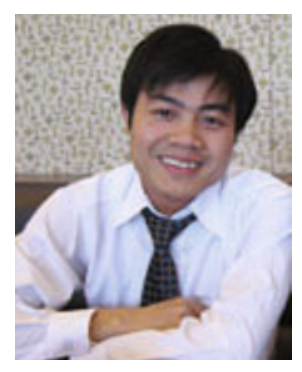

Nguyen Van Nghiem graduated master degree in Chung Nam National University (in 2008). Now, he is a doctoral student in University of Science and Technology (UST, South Korea). His major is resources recycling, and his research activities focus on recovering metals from waste solutions using solvent extraction and ion exchange.

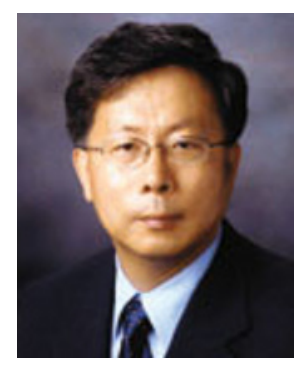

Dr. Jae-chun Lee is currently Principal Researcher in the Mineral Resources Research Division at the Korea Institute of Geoscience and Mineral Resources (KIGAM), and an adjunct professor of Resources Recycling at the University of Science and Technology (UST) at Daejeon, Korea. His research deals with leaching, separation and purification of metals from primary and secondary resources, and material preparation by aqueous processing.

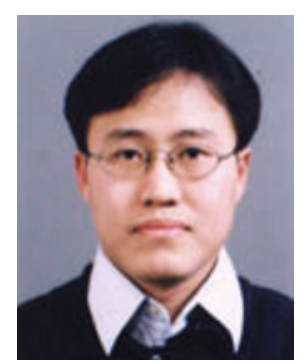

Dr. Soo-kyoung Kim is a Senior Researcher in the Mineral Resources Research Division of Korea Institute of Geoscience and Mineral Resources (KIGAM). His research focuses on the refining of metals by the electrochemical method and hydrometallurgical recycling of industrial wastes.

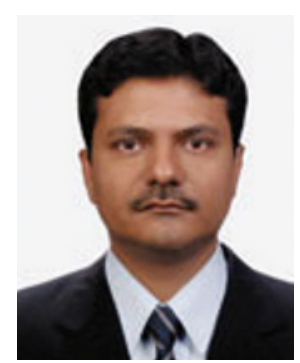

Dr. Manis Kumar Jha is currently Assistant Director in Metal Extraction \& Forming Division, National Metallurgical Laboratory (Council of Scientific \& Industrial Research), Jamshedpur, India. His area of expertise is metal extraction from ores, concentrates and secondary \& recycling of metals from solid wastes and liquid effluents using hydrometallurgical processes. 


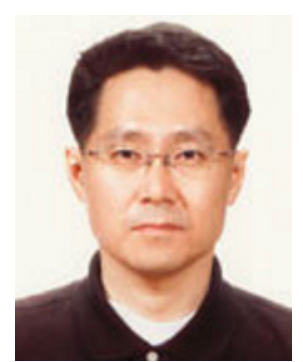

Dr. Kang-Sup Chung is currently Principal Researcher in the Mineral Resources Research Division at the Korea Institute of Geoscience and Mineral Resources (KIGAM). His research deals with synthesis of nanosize colloidal gold and its optical properties and recently focuses on the recovery of Li from seawater using nano-manganese oxide adsorbent.

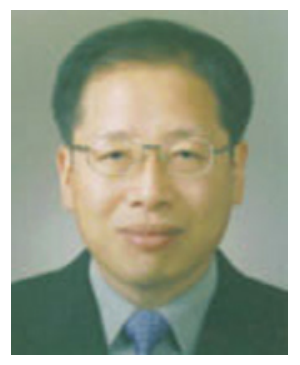

Dr. Jinki Jeong is currently Principal Researcher in the Mineral Resources Research Division at the Korea Institute of Geoscience and Mineral Resources (KIGAM), and an adjunct professor of Resources Recycling at the University of Science and Technology (UST) at Daejeon, Korea. His research focuses on metal separation and process optimization in the processing of waste water treatment and recycling of industrial wastes.

\section{References}

1 S. Rengaraj, J.W. Yeon, Y.h. Kim, Y.j. Jung, Y.k. Ha, W.H. Kim, Journal of Hazardous Materials, 2007, 143, 469

2 C. Tasdelen, S. Aktas, E. Acma, Y. Guvenilir, Hydrometallurgy, 2009, 96, 253

3 A.G. Chmielewski, T.S. Urbtiski, W. Migdal, Hydrometallurgy, 1997, 45, 333

4 J.D. Miller, S.D. Alexandratos, US patent, 1990, 4894407

5 H.J. Byoung, Y.Y. Park, J.W. An, S.J. Kim, T. Tran, M.J. Kim, Hydrometallurgy, 2008, 95, 262

6 H. Narita, M. Tanaka, K. Morisaku, T. Abe, Hydrometallurgy, 2006, 81, 153

7 Y.F. Shen, W.Y. Xue, Separation and Purification Technology, 2007, 56, 278
8 T. Ogata, Y. Nakano, Water Research, 2005, 39, 4281

9 C.P. Gomes, M.F. Almeida, J.M. Loureiro, Separation and Purification Technology, 2001, 24, 35

10 N.V. Nguyen, J.-c. Lee, M.K. Jha, K.K. Yoo, J.K. Jeong, Hydrometallurgy, 2009, 97, 237

11 F.J. Alguacil, P. Adeva, M. Alonso, Gold Bulletin, 2005, 38, 9

12 A. Ramesh, H. Hasegawa, W. Sugimoto, T. Maki, K. Ueda, Bioresource Technology, 2008, 99, 3801

13 R. Rajasingam, N.S. Jayasinghe, F.P. Lucien, T. Tran, Minerals Engineering, 2006, 19, 896

14 H. Zhang, D.B. Dreisinger, Hydrometallurgy, 2002, 66, 67

15 H. Zhang, D.B. Dreisinger, US patent, 2003, 6632264 B2

16 O. Marsden, I. House, The chemistry of gold extraction, 2005, second edition, 343

17 E. Latif, D. Sahan, A. Basaran, S. Mustafa, Environ Monit Assess, 2007, 132, 331

18 H. Koshima, Analytical Sciences, 1986, 2, 255

19 M. Laatikainen, E. Paatero, Hydrometallurgy, 2005, 79, 154

20 E. Latif Elci, S. Mustafa, E.B. Buyuksekerci, Analytical Sciences, 2003, 19, 1621

21 B.G. Harris, J.P. Barry., S. Monette, US patent, 1990, 5028260

22 R. Radulescu, O. Filcenco, E. Panture, L. Grigoras, Politehnica, 2008, 53, 137

23 K. Amy., US patent, 2000, 6150279

24 M.K. Jha, R.R. Upadhyay, Jae-chun Lee, Vinay Kumar, Desalination, 2008, 228, 97

25 S. Lagergren, Kungliga Svenska Vetenskapsakademiens Handlingar, 1898, 24-4, 1

26 S. Rengaraj, K.H. Yeon, S.Y. Kang, J.U. Lee, K.W. Kim, and S.H. Moon, Journal of Hazardous Materials, 2002, 92, 185

27 G. Fethiye, E. Pehlivan, Journal of Hazardous Materials, 2006, B136, 330

28 B. Smith, Infrared spectral interpretation: A Systematic Approach. CRC Press LLC, USA, 1999, 108

29 M.D. Saikia, Colloids and Surfaces A: Physicochemical and Engineering Aspects, 2008, 315, 196 